\title{
Restoration of Escherichia coli Strain B after $\gamma$-irradiation
}

\author{
By A. J. FORAGE AND N. E. GILLIES \\ Department of Biology as Applied to Medicine, \\ Middlesex Hospital Medical School, London W. 1
}

(Received 16 April 1964)

\begin{abstract}
SUMMARY
The fraction of bacteria of a proline-requiring auxotrophic strain of Escherichia coli strain B which was able to originate macrocolonies on a defined nutrient medium after exposure to $\gamma$-rays under anoxic conditions was markedly increased when the organisms were deprived of proline or were treated with chloramphenicol for the initial period after irradiation. Either treatment was equally effective and the maximum degree of survival which was obtained was above that observed when the cells had been incubated throughout on a proline +inorganic salts + glucose medium. The depression in survival caused by including $\mathrm{NaCl}$ in the defined nutrient medium, on which the irradiated bacteria were grown, was completely eliminated by both treatments. 'Rescue' appears to depend on the temporary inhibition of protein synthesis.
\end{abstract}

\section{INTRODUCTION}

The amount of damage which becomes apparent in irradiated micro-organisms may be modified by a variety of treatments applied to the organisms either before or after irradiation. For example, the survival of Escherichia coli strain B after exposure to ultraviolet (u.v.) or ionizing radiation depends on the nature of medium on which they are plated (Robert \& Aldous, 1949; Alper \& Gillies, 1958 $a, b, 1960$ ). Alper \& Gillies $(1958 b, 1960)$ showed that there was good correlation in this strain between high survival and slow growth after irradiation. Thus, the survival of the irradiated organisms was higher on an inorganic salts glucose medium, on which the rate of growth was slow, than on nutrient medium on which the bacteria grew more rapidly. However, survival on the nutrient medium can be markedly increased when growth of the bacteria is inhibited by chloramphenicol for an interval immediately after irradiation (Gillies \& Alper, 1959). Chloramphenicol is believed to inhibit protein synthesis in bacteria specifically (Gale \& Foulkes, 1953; Wisseman, Smadel, Hahn \& Hopps, 1954). It appears, therefore, that the survival of that fraction of organisms which can be rescued is dependent on the inhibition of protein synthesis during the initial post-irradiation period. Further data in support of this conclusion were obtained from experiments on u.v.-irradiated auxotrophic mutants of $E$. coli $\mathbf{B}$, which showed that considerable rescue could be effected when utilization of an amino acid, but not utilization of thymine, was inhibited immediately after irradiation (Gillies, 1961). The same effect was observed in a proline-requiring strain of $E$. coli B deprived of proline or treated with chloramphenicol for the initial period after X-irradiation (Gillies, 1963). The present paper describes a series of experiments made to determine in more detail the conditions under which the proline-requiring 
strain $E$. coli B 33 could be rescued after exposure to ionizing radiation. These experiments were:

(a) Determination of the effect on survival of depriving the bacteria of proline for an initial period after exposure to $\gamma$-rays, by incubating the irradiated bacteria for various periods on a nutrient medium of defined composition which lacked proline, before transferring them to the defined nutrient medium containing proline.

(b) Comparison of the effect of the above treatment with that of incubating irradiated bacteria on the defined nutrient medium containing chloramphenicol, before transferring them to fresh defined medium without chloramphenicol.

(c) Determination of the effect of incorporating $\mathrm{NaCl}$ into the defined nutrient medium on the extent of rescue brought about by proline deprivation or by chloramphenicol treatment. Previously chloride was found to decrease the number of irradiated bacteria of Escherichia coli в able to form macrocolonies on a nutrient medium (Alper \& Gillies, 1958b).

\section{METHODS}

Media. The defined glucose medium used was that devised by Davis (quoted by Lederberg, 1950). The defined nutrient medium, called medium M19, consisted of the defined salts glucose medium supplemented with amino acids and nitrogenous bases; its composition was the same as that of the medium $N$ of Gillies (1961) except that it lacked isoleucine and inosine. Proline (10 $\mu \mathrm{g} . / \mathrm{ml}$.$) , chloramphenicol (5 \mu \mathrm{g} . /$ ml.) and $\mathrm{NaCl}$ ( 5 g./l.) were added as required. When examining the effect of chloramphenicol proline was always included in the growth medium. Strain Escherichia coli $\mathrm{B} 33$, a proline-requiring mutant, was isolated after induction with u.v. radiation from the strain of $E$. coli B used in previous experiments (Alper \& Gillies 1958 $a, b$, 1960; Gillies \& Alper, 1959). The methods used in isolating and identifying the auxotrophic mutant were as previously reported (Gillies, 1961).

Preparation of bacterial suspensions for irradiation. The strain of Escherichia coli B33 was grown in Oxoid nutrient broth, supplemented with proline (10 $\mu \mathrm{g} . / \mathrm{ml}$.), at $37^{\circ}$ for $18 \mathrm{hr}$. The bacteria, which were then in the stationary phase of growth, were harvested by centrifugation, washed 3 times in $\mathrm{m} / 15$ phosphate buffer $(\mathrm{pH} 7)$ and finally resuspended in buffer to a concentration of about $6 \times 10^{6} \mathrm{bacteria} / \mathrm{ml}$.

Irradiation of bacteria. Bacteria were exposed to radiation from a ${ }^{60} \mathrm{Co}$ source (Vickers-Armstrong's MK. IV Hotspot Irradiation Unit) in the vessel shown in Fig. 1. Oxygen-free $\mathbf{N}_{2}$ was bubbled vigorously through the suspension during irradiation, since previous experiments by Alper (1961), Alper \& Gillies (1958a) and Gillies \& Alper (1959) had shown that more rescue of irradiated bacteria could be obtained if they had been irradiated in anoxic rather than in oxygenated conditions. The dose rate, as measured by ferrous sulphate dosimetry (Miller \& Wilkinson, 1952), was $\mathbf{2 \cdot 2} \mathrm{Kr}$./min.

Treatment of bacteria after irradiation. Suitable dilutions of the suspension of irradiated bacteria and also samples of un-irradiated organisms were dispensed on to cellophan carriers lying on the surface of the growth media previously warmed to $37^{\circ}$. This technique, which has been described (Alper \& Gillies 1958 b), allows bacteria to be transferred rapidly from one medium to another. Bacteria were incubated at $37^{\circ}$ overnight and the macrocolonies counted. 


\section{RESULTS}

The $\gamma$-ray sensitivity of the proline-requiring Escherichia coli strain B 33 was the same as that of the parent strain $E$. coli $\mathrm{B}$, and it also responded to the conditions of

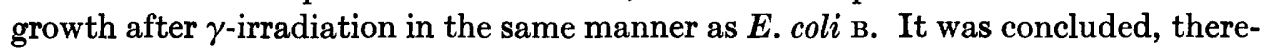
fore, that the mutagenic treatment had not caused changes in radiobiological characteristics other than those specifically concerned with the proline requirement. As was found for $E$. coli B (Alper \& Gillies, 1960), the survival of irradiated $E$. coli strain в 33 on defined medium and on defined medium $+\mathrm{NaCl}$ was the same, and no effect of $\mathrm{NaCl}$ was observed. As shown in Fig. 3, however, a marked decrease in the number of irradiated bacteria able to form colonies was observed when $\mathrm{NaCl}$ was included in the M19 medium.

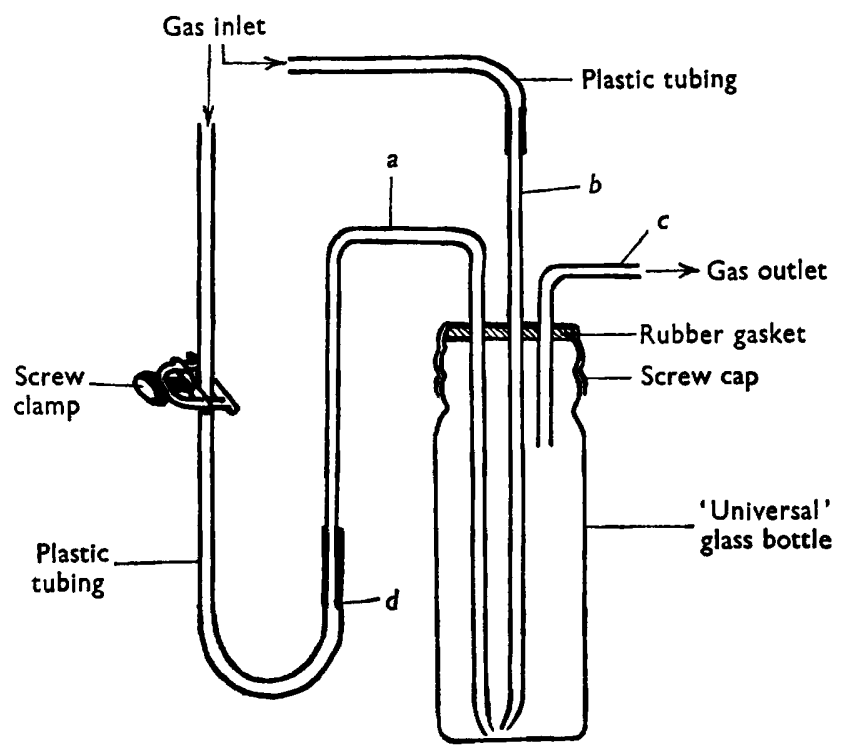

Fig. 1. Diagram of vessel in which bacterial suspensions were irradiated. $a, b$ and $c$ are glass tubes ( $4 \mathrm{~mm}$. diam., $2 \mathrm{~mm}$. bore). The bottle is half-filled with the bacterial suspension and gas is bubbled through tubes $a$ and $b$. To remove a sample from the vessel, the screw clamp is closed and the sample is collected at $d$. Tube $c$ is then opened, the plastic tubing replaced on tube $a$, and the clamp opened so that bacterial suspension remaining in $a$ is forced back into the vessel. In this way the gas conditions are kept constant during sampling.

The effect of inhibiting the growth of irradiated Escherichia coli strain в 33 on $\mathrm{M} 19$ medium with or without $\mathrm{NaCl}$, either by deprivation of proline or by treatment with chloramphenicol, is illustrated in Fig. 2. It can be seen that considerable and equal rescue of irradiated bacteria was effected by deprivation of proline or by treatment with chloramphenicol. Inhibition of the growth of the bacteria for about $5 \mathrm{hr}$ on a medium lacking $\mathrm{NaCl}$ was required to produce maximum rescue after a dose of 22 krads of $\gamma$-radiation under anoxia. When bacteria were exposed to smaller doses of $\gamma$-radiation a shorter period of post-irradiation treatment was sufficient to effect maximum rescue. However, when $\mathrm{NaCl}$ was included in the medium, the growth of 
the bacteria must be inhibited for a longer period, about $8 \mathrm{hr}$ after exposure to 22 $\mathrm{krad}$, to increase survival to a maximum value. Despite the fact that there was a tenfold difference in the fraction of bacteria which survived, depending on whether $\mathrm{NaCl}$ was included in the growth medium or not, there was little difference in the maximum survival obtainable after growth had temporarily been inhibited. Thus, after a dose of 22 krads of $\gamma$-radiation approximately a 50 -fold increase in survival (from 0.5 to $30 \%$ ) was effected on medium containing $\mathrm{NaCl}$, and sixfold increase (from 6 to $35-45 \%$ ) on a medium lacking $\mathrm{NaCl}$.

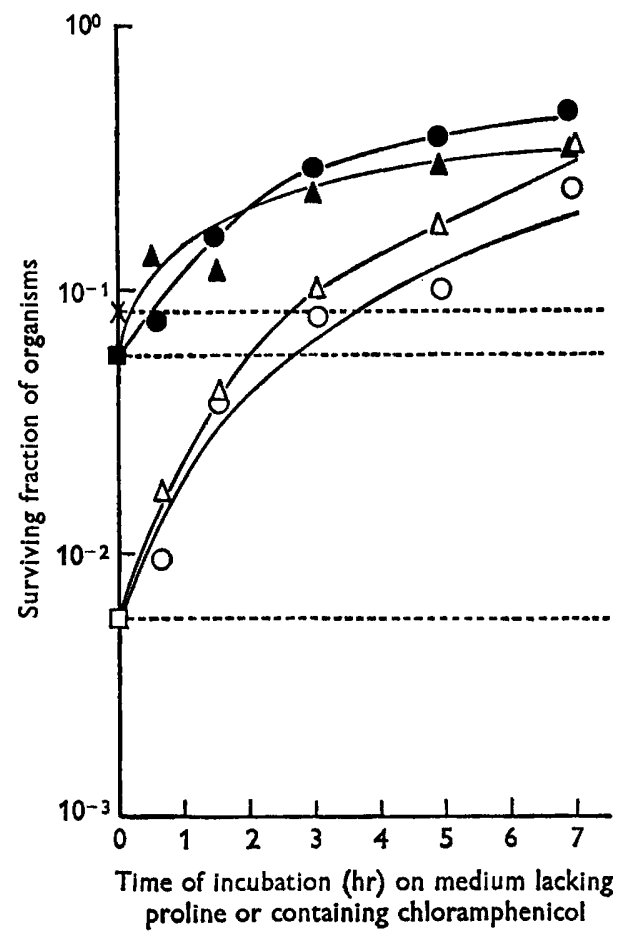

Fig. 2. Survival of stationary-phase Escherichia coli strain в 33 after exposure to 22 krads $\gamma$-radiation under anoxia.

Level of survival of bacteria incubated throughout on: $\times$, defined salts glucose medium + proline; $\square$, M19 medium + proline; $\square$, M19 medium + proline + NaCl. Survival of bacteria incubated on first medium for the intervals indicated before transfer to second medium.

1st medium

- M19

O $\mathbf{M 1 9}+\mathbf{N a C l}$

A M19 + proline + choramphenicol (CMP)

$\triangle \mathrm{Ml} 9+$ proline $+\mathrm{NaCl}+\mathrm{CMP}$

\section{2nd medium}

M19+proline

$\mathrm{M19}+$ proline $+\mathrm{NaCl}$

M19+ proline

- M19+proline + NaCl

The points on the figure indicate the mean value of 6-18 separate observations for individual treatments. To preserve clarity, experimental errors have been omitted, but the $95 \%$ confidence limits of the majority of the points fall within $\pm 20 \%$ of the mean, with a few as high as $\pm 30 \%$.

Figures 3 and 4 show dose-effect curves for rescued and unrescued cells. Figure 4 illustrates in more detail the initial portions of the survival curves shown in Fig. 3 and it can be seen that the extrapolation number (Alper, Gillies \& Elkind, 1960) of the 
curve for rescued bacteria was greater than 1, whereas the extrapolation number of the curves for unrescued cells was unity. The number of unirradiated bacteria which originated macrocolonies was not altered by incubating them on different growth media, by temporary deprivation of proline or by treatment with chloramphenicol.

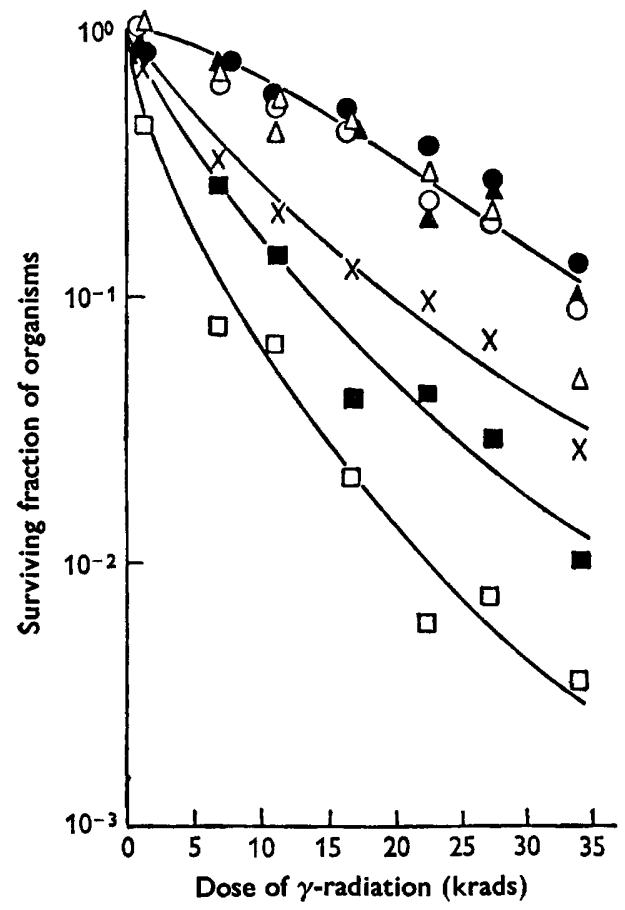

Fig. 3

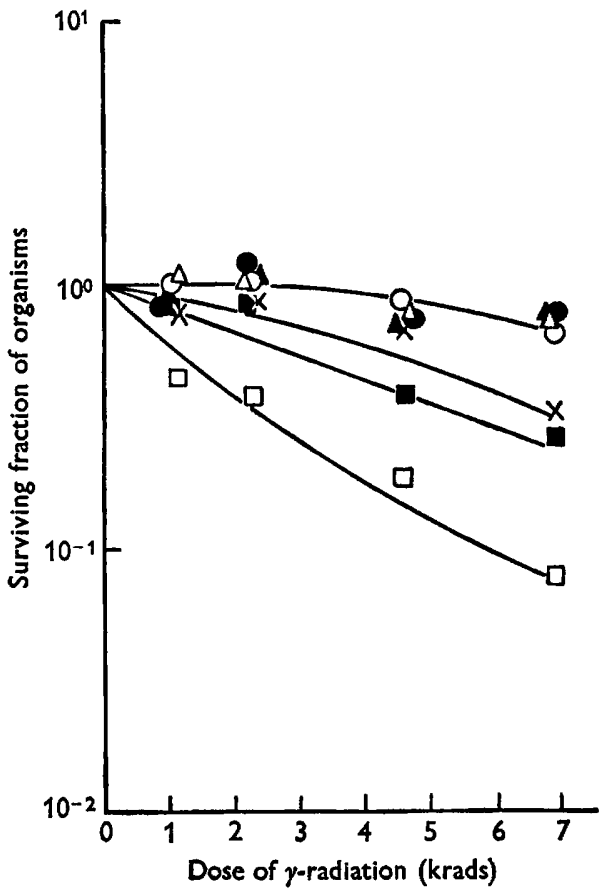

Fig. 4

Fig. 3. Survival curves of stationary phase Escherichia coli strain в 33 incubated under different conditions after exposure to $\gamma$-radiation under anoxia.

Survival of bacteria incubated throughout on: $x$, defined salts glucose medium + proline, 口, $\mathbf{M} 19$ medium + proline ; $\square$, M19 medium + proline $+\mathrm{NaCl}$.

Maximum level of survival of bacteria incubated on first medium before transfer to second medium.

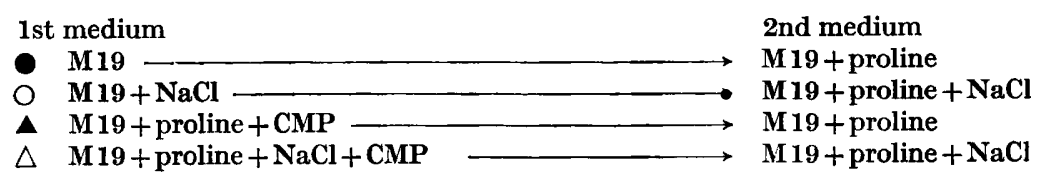

Fig. 4. The initial portions of the survival curves of stationary-phase Escherichia coli strain B 33 shown in Fig. 3 but with the dose scale expanded by a factor of 5 . Treatments are denoted by the same symbols as used in Fig. 3.

\section{DISCUSSION}

The results confirm that the fraction of $\gamma$-irradiated bacteria of Escherichia coli strain в 33 which are capable of originating macrocolonies can be markedly increased when the bacteria are prevented from utilizing proline or are treated with chloramphenicol for an interval after irradiation. It seems probable that this 'rescue' is a consequence of inhibiting protein synthesis in the organisms. The modes of action by 
which the two treatments inhibit protein synthesis, however, are not likely to be identical. Proline deprivation will lead to inhibition of synthetic reactions which involve proline, whereas chloramphenicol appears to act by preventing the attachment of messenger RNA to ribosomal RNA (Jardetzky \& Julian, 1964). The fact that the extent of rescue effected by the two methods is approximately the same may be fortuitous, for the efficiency and pattern of rescue obtained by chloramphenicol is dependent on the concentration of inhibitor used (Gillies; unpublished observation). Data presented by Gillies (1963) suggested that treatment with chloramphenicol ( $5 \mu \mathrm{g} . / \mathrm{ml}$.) was more effective in promoting rescue than was deprivation of proline, but this finding is not supported by the present work in which incubation without proline was as efficient in increasing survival as was chloramphenicol treatment. The reason for this is unknown, but the sensitivity of $E$. coli strains to various antibiotics appears to vary over prolonged periods. Also, the rescue which can be effected by deprivation of proline increased survival above that observed when the organisms had been incubated throughout on the defined salts + glucose medium.

The presence of $\mathrm{NaCl}$ in the post-irradiation nutrient medium was previously found to decrease the fraction of bacteria able to form colonies. However, inhibition of division for a limited period appears to eliminate completely the effect of $\mathrm{NaCl}$. At the same time $\mathrm{NaCl}$ had little effect on the extent and pattern of rescue of the irradiated bacteria, although the time required to effect maximum rescue was longer when $\mathrm{NaCl}$ was included in the incubation medium.

Previous work has shown that a considerable fraction of u.v.-irradiated organisms of amino acid requiring mutants of Escherichia coli $\mathbf{B}$ may be rescued if they are deprived of the essential amino acid for the initial post-irradiation period (Gillies, 1961). It is therefore tempting to suggest that inhibition of protein synthesis prevents the expression of damage which is common to u.v.-, $\mathbf{X}$ - and $\gamma$-irradiation. U.v.-radiation will be selectively absorbed in nucleic acids and their precursors. Barner \& Cohen (1956) postulated that cell death may be due to an imbalance in cytoplasmic and nuclear synthesis after irradiation. When protein synthesis is temporarily inhibited the development of a lethal imbalance in synthesis may be temporarily prevented. However, the nature of such an imbalance is obscure and, as pointed out by Okagaki, Tsubota \& Sibatani (1960), is not simply a matter of protein synthesis continuing in the absence of DNA synthesis.

The present results support previous suggestions (Alper, 1961; Alper \& Gillies, $1958 a, b)$ that damage which is expressed in Escherichia coli $\mathbf{B}$ is the summation of at least two types of damage, one of which may be modified by post-irradiation treatment, while the other cannot. Alper (1961) postulated that these different types of damage may be due to absorption of radiation energy in at least two different sites in the cell. Although it may be that the site in which damage can be modified is associated with DNA, there are no clues which might indicate the nature of the other site.

The recent demonstration that the property of resistance to radiation action can be transferred genetically from one strain of Escherichia coli to another (Adler \& Copeland 1962; Howard-Flanders, Boyce, Simson \& Theriot, 1962) suggests that rescue of $E$. coli organisms may be dependent on the action of cellular reactivating enzymes after irradiation. However, the present work does not easily lend support to this interpretation, since conditions which inhibit protein synthesis are unlikely 
to bring about rescue by such a mechanism. It is possible that reactivating enzymes are continuously synthesized in normal cells and that they only act after exposure to radiation, but it would be very unusual for an enzyme to exist in the absence of its substrate.

We are grateful to Miss Barbara Porter for skilful technical assistance. One of us (A. J. F.) is indebted to the Medical Research Council for a studentship.

\section{REFERENCES}

Adler, H. I. \& Copeland, J. C. (1962). Genetic analysis of radiation response in Escherichia coli. Genetics, 47, 701.

ALPER, T. (1961). Variability in oxygen effect observed with micro-organisms. II. Escherichia coli B. Int. J. Rad. Biol. 3, 369.

Alper, T. \& Gillies, N. E. (1958a). Dependence of the observed oxygen effect on the post-irradiation treatment of micro-organisms. Nature, Lond. 181, 961.

AlPer, T. \& Gillies, N. E. (1958b). Restoration of Escherichia coli strain B after irradiation; its dependence on suboptimal growth conditions. J. gen. Microbiol. 18, 461 .

Alper, T. \& Gillies, N. E. (1960). The relationship between growth and survival after irradiation of Escherichia coli strain B and two resistant mutants. J. gen. Microbiol. 22, 113.

Alper, T., Gillies, N. E. \& Elkind, M. M. (1960). The sigmoid survival curve in radiobiology. Nature, Lond. 186, 1062.

Barner, H. D. \& Cohen, S. S. (1956). The relation of growth to the lethal damage induced by ultraviolet irradiation in Escherichia coli. J. Bact. 71, 149.

Gale, E. F. \& Foulkes, J. P. (1953). The assimilation of amino acids by bacteria 15: Action of antibiotics on nucleic acid and protein synthesis in Staphylococcus aureus. Biochem. J. 53, 493.

Gillies, N. E. (1961). The use of auxotrophic mutants to study restoration in Escherichia coli B after ultra-violet irradiation. Int. J. Rad. Biol. 3, 379.

Gillies, N. E. (1963). Reported in Radiation Effects in Physics, Chemistry and Biology. Ed. by M. Ebert and A. Howard, p. 182. Amsterdam: North-Holland Publishing Company.

Gillies, N. E. \& AlPER, T. (1959). Reduction in the lethal effects of radiations on Escherichia coli B by treatment with chloramphenicol. Nature, Lond. 183, 237.

Howard-Flanders, P., Boyce, R. P., Simson, E. \& Theriot, L. (1962). A genetic locus in $E$. coli $\mathrm{K} 12$ that controls the reactivation of UV-photoproducts associated with thymine in DNA. Proc. nat. Acad. Sci., Wash. 48, 2109.

JARDETZKY, O. \& Julian, G. R. (1964). Chloramphenicol inhibition of polyuridylic acid binding to Escherichia coli ribosomes. Nature, Lond. 201, 397.

LEDERBERG, J. (1950). Isolation and characterisation of biochemical mutants of bacteria. Meth. Med. Res. 3, 5.

Miller, N. \& Wilkinson, J. (1952). Actinometry of ionizing radiations. In Radiation Chemistry, Disc. Faraday Soc. no. 12, p. 50.

Oragaki, H., Tsubota, \& Sibatani, A. (1960). Unbalanced growth and bacterial death in thymine-deficient and ultraviolet irradiated Escherichia coli. J. Bact. 80, 762.

Roberts, R. B. \& AldDous, E. (1949). Recovery from ultraviolet irradiation in Escherichia coli. J. Bact. 57, 363.

Wisseman, C. L., Smadel, J. E., Hahn, F. E. \& Hopps, H. E. (1954). Mode of action of chloramphenicol. 1. Action of chloramphenicol on assimilation of ammonia and on synthesis of proteins and nucleic acids in Escherichia coli. J. Bact. 67, 662. 